\title{
Translation Process of Verbal to Graph Representation: Transitional Representation
}

\author{
Dwi Rahmawati ${ }^{1 *}$, Rahmad Bustanul Anwar ${ }^{1}$, S E Supriyatun ${ }^{2}$ \\ ${ }^{1}$ Department of Mathematics Education, Universitas Muhammadiyah Metro, Metro34381, Indonesia \\ ${ }^{2}$ SMPN 4 Metro, Metro34381, Indonesia \\ "Corresponding author.Email: dwirahmawati1083@gmail.com
}

\begin{abstract}
Translation of representation is one representation process which takes an essential role in mathematics learning. Translation capability shown level of students' conceptual understanding. Some processes of translation involve transitional representation. This study aims to describe the occurrence of the process of translating verbal representations to graphs involving transitional representations. This research is a qualitative research. The subject of this research was of the $4^{\text {th }}$ and $6^{\text {th }}$ semester of Mathematics Education department and it was determined by using purposive sampling. The data collection was done by think-aloud tests and interviews. The results shown that there are two types of transitional representation in the process of translation of verbal to the graph representation, i.e. symbolic and numerical representation. The student translates the verbal representation to the graph through two translational processes. The student translates the verbal representation to a symbolic or numerical representation of the representation transition and then translates the symbolic and numerical representation of the representation transition to a graphic representation. The results of this study are expected to increase the findings of previous research and as a consideration in designing learning model.
\end{abstract}

Keywords: mathematics learning, translation process, verbal to graph

\section{INTRODUCTION}

Translations between forms of representation is one of the multiple representation capabilities. Translation is a process of change from one form of representation to another form of representation [1]. While translation as a cognitive process in transforming information contained in a form of representation to another form of representation [2]. Through translation between representations, students can enhance their understanding and express ideas through various means [3]. The ability of translation between representations can also be an indicator of students' mathematical understanding. A deep understanding of mathematics is a compulsion for every student since mathematics plays an important role in the development of the recent technology [4]. Therefore, the teacher should offer the opportunity to the students to develop the translation skills between representations within the learning process.

Some translation between representations require more than one process of translation or in other words, the process of translation occurs indirectly. While there is a translation that requires only one translation process, i.e. the direct process of translation. Indirect translations, for instance, in translating from symbol representations to graphic representations, students use a table transition representation. While the direct translation occurs if it is not through another transition representation. The use of transitional representation is one of the difficulty factors of the translation process [5]. Where students have to do the translation process more than one. The student translates from the source representation to the transition representation, then translates from the transition representation to the target representation.

Students as prospective teachers are expected to be able to do translation between forms of representation for the provision of facilitating students in doing the translation on learning in the class later. As stated by National Council of Teachers of Mathematics [6], in mathematics learning, teachers are expected to be able to facilitate students in 1) generating and applying representation to organize, note, and communicate mathematical ideas; 2) determining, applying, and conducting process of translation between representations to solve problem; 3) applying representation to generate a model and interpretation physical, social, or mathematical occurrence.

However, there are still numerous studies that confirm student difficulties related to translation between representations in function representation. Some studies have revealed that translating verbal representations to graphs is the most difficult translation [5], [7], [8]. Identical findings were also revealed by Celik \& Arsal [9], stating that students are more successful at determining the correct graph among others than constructing a graph. Likewise, in research conducted by Adu-Gyamfi, Bosse, \& Chandler [10] related to the sources of error in translation of verbal representation to algebra is one of the low understanding of verbal information. Verbal information can be done through texts interpretation by drawing situations based on obtained experience [11]. The ability to interpret text with images is indispensable in the translation of verbal representation. It 
needs further research related to the translation process from verbal representation to tables or graphs [10]. Representation translation is essential in mathematical understanding and problem solving, hence it is necessary to understand how the process of representational translation takes place. Existing research is still very limited in providing a detailed description of the process of representational translation. According to the results of preliminary research on mathematics education students, it shows that there are still many students who have not been able to do the translation from verbal to graph. The capability of translation from verbal to graph representation is still very limited. Students have not been able to construct a graph corresponding to a given verbal representation. Such circumstances should be overcome since students of Mathematics Education is a prospective teacher of mathematics who should be able to develop the ability of translation on their students. Therefore, it is important to understand how mathematics education students translate representation from verbal to graph in detail.

This study describes the process of translating verbal representations to graphs involving transitional representations. So, it can know the types of transitional representation used in representation translation from verbal to graphs. The results of this study are expected to be used to reflect and evaluate the process of translating verbal representations to graphs, to identify students' difficulties in the process of translating verbal representations to graphs and suitable scaffolding, to be used as consideration materials in designing appropriate learning design, thus it optimizes students' capability in translation process. In addition, the findings of this research are expected to be able to complete the previous research.

\section{METHOD}

This study aims to revealing the process of translating verbal representations to graphs involving transitional representations. This research was a qualitative research. This research involved students from Mathematics Education. The subject of this research was of the 4th and 6th semester of Mathematics Education department. Purposive sampling was used to determine the research subject.

This research employed two types of instrument, namely primary instrument, andauxiliary instrument. The primary instrument was the researchers and the auxiliary instrument was test items and interviews guideline. Auxiliary instruments in the form of test items and interview guidelines have been validated by two mathematics education experts before use. Both instruments have been declared eligible to use.

The data collection in this research was done through thinkaloud test and interview. In this study, students were asked to express verbally what was thought during the completion of test items (think aloud). After the student completed the given test, the researcher conducted an interview to reveal the student's reason when taking a certain step. Researchers recorded all verbal expressions with recorders and note down students' behaviour.
Then, the researchers analysed written and verbal data which were obtained during data collection to obtain a depiction of the process of representational translation which involves transitional representation. The data analysis of this research consisted of transcribing data of the entire verbal data to written form data, examining the obtained data, reducing primary data, coding data, describing data, and generating a conclusion.

\section{RESULTS AND DISCUSSION}

The process of translating verbal representation to the graph by the students occurred indirectly involving two processes of translation. This translation process of the students is a transitional representation. There are two types of translations made by students that involve symbolic and numerical representation of transitions. The process of translation that involves a symbolic representation of the students is translating the verbal representation (source) to the symbolic then translating the symbolic representation to the graph (target). While the process of translation that involves the numerical representation is translating verbal representation (source) to the numerical representation and then translating the numerical representation to the graph (target).

First, the translation process involving symbolic transitional representation, in translating verbal representation to the graph, students involve two translation process. In this, students understand that to construct or draw a graph representing a given verbal problem requires the equation of the verbal problem. Prior to constructing the graph, the student transforms the identified information into the symbolic form of the equation. Students determine the equation as a function that states the relationship between the distance of both cars and the time of the given event. Where the distance between both cars is a dependent variable and time as an independent variable. Students connect the verbal components that have been exemplified by the concept which they understand to form the equation. Accessing and combining initial knowledge will help to find a solution [12].

Students perform a series of algebraic operations to determine the relationship between the distance between the two cars and time. Success in determining equations in algebraic form depends on the ability to align verbal structures with symbolic structures [10]. Students determine the equations that represent the verbal representation that is the basis of forming a graphical representation (target). Janvier in Bosse, Gyamfi, \& Chandler [5], refers to modelling, i.e., adjusting verbal information to formulas (equations). The equation is shown by the results of students' written answers in Figure 1.

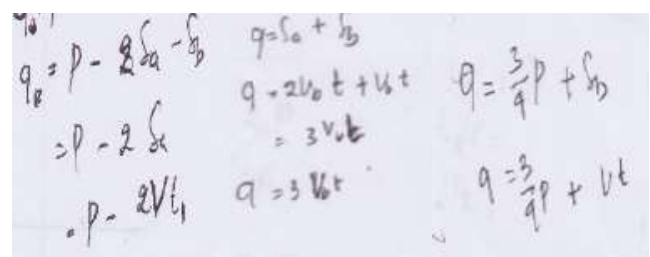

Figure 1 Written answer in determining equation 
coordinates obtained in the field of Cartesian coordinates. Then the students draw a line that connects the coordinates of the point. Students draw a line based on the acquired equation. Figure 2 shows the results of student's written answers related to the graph obtained.

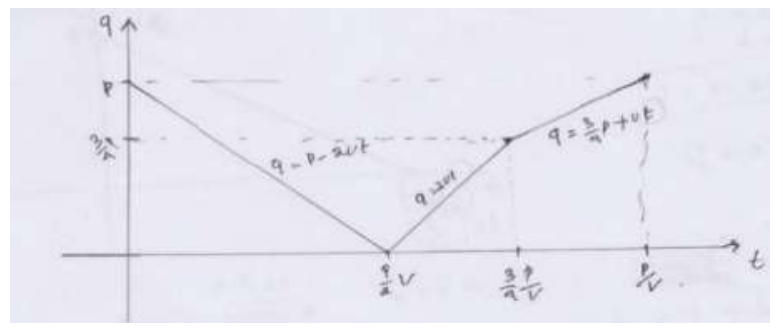

Figure 2 Student's written answer during graph sketching

Second, a process of translation involving the representation of numerical transitions that is in translating verbal representations to graph, student involves two processes of translation. Students understand that in order to construct a graphic of verbal problems given, it requires case examples of such verbal problems. Initially, students generated case example as the distance of $\mathrm{X}$ city to $\mathrm{Y}$ city is 20 , after passing, the speed of car A is 2 and the speed of car B is 1 . Hereinafter, students connect the case example with the concept which they obtained to determine the distance between the two cars for the case. This is reflected in the results of students' written answers in the following Figure 3. the horizontal axis $\mathrm{t}$ as time and vertical axis $\mathrm{q}$ as the distance between the two cars. After sketching the field of Cartesian coordinates, the students placed the point

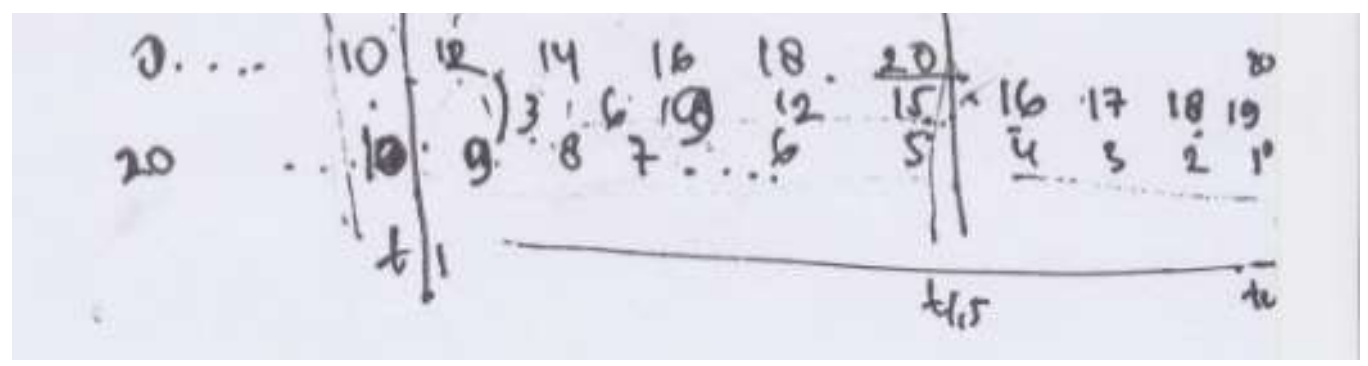

Figure 3 Students' written answer in determining the distance of both cars from case example

Students determine the basic idea to construct a graph by creating a case example. Students make case examples to check for the simpler occurrence of given verbal occurrence. Using certain case example, students will be easier to understand so that a general graph of component components can be obtained. Students make case examples and then look at the pattern of distance change relationship of the two cars on the time change and proceed with generating conclusion through symbol. The student determines the case example and then identify numerically the pattern of distance change of the two cars to time change representing the verbal representation as the basis for forming the target representation (graph). By looking at patterns, students can look for regularities that make it easy to define graphics components. The student determines the case example numerically as a transitional representation to construct a target (verbal) representation.

Numerical representation could be used to obtain a strong understanding regarding the certain issue and as a means of investigating the certain case [15]. This shows that the process of translation from verbal representation to graph occurs indirectly or through a numerical transition representation. The transitional representation of numerical in the translation process from verbal to the graph used by the students is in line with the results found by Bosse, Gyamfi, \& Chandler [5] explaining that the translation from verbal to graph through an intermediate representation of tables is also a numerical representation. Transitional representation can assist the student in transferring information to the target representation. Through a numerical transition representation, it makes students easier 
to prepare the graph-forming components required for constructing graphics targets.

According to the case example generated, to determine graph-forming components, students generate a conclusion of a case, in general, using the symbol. Students construct graphic representation by determining graph-forming components in the form of the horizontal axis, vertical axis, the coordinate of the point (ordered pair), members of the domain and members of range, and slope. Students associate the pairing relationship between the time and distance of the two cars that have been obtained as the ordered pair which is the point coordinates on the graph. The results of students' written answers are presented in the following Figure 4.

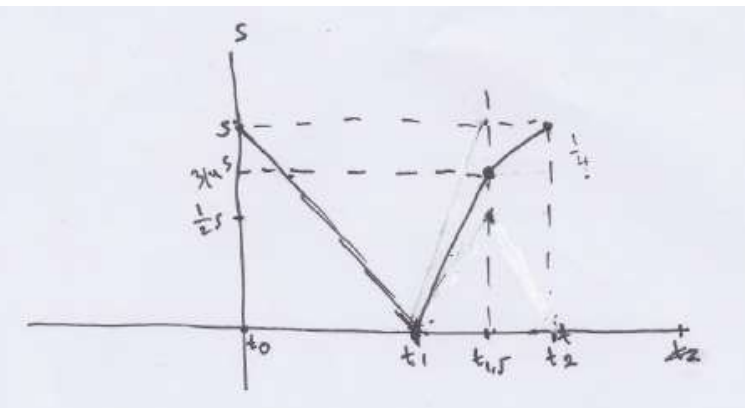

Figure 4 Students' written answer during graph sketching

According to the aforementioned description, the process of translating verbal representation to the graph by students takes place through two processes of translation. The students translate the verbal representation (source) to the transition representation, then translate the transition representation to the graph representation (target). The translation process involves symbolic and numerical representation. Figure 5 is an overview of the process of translating verbal representations to the graph.

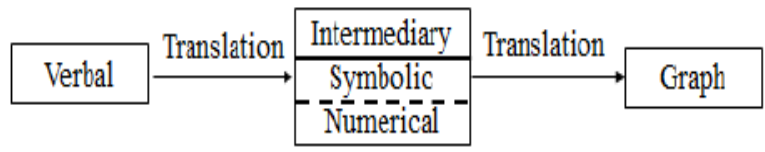

Figure 5 Translation process of verbal representation to graph

\section{CONCLUSION}

According to the findings of the research explained above, it can be concluded that there are two types of transitional representation used by students in the process of translation of verbal representation to the graphic representation, i.e. symbolic and numerical representation. First, students perform the process of translating verbal representations to graphs by means of a symbolic transition representation in which students translate verbal representations to symbolic transition representations and then translating representations of symbolic transitions to graphic representations. Second, students perform the process of translating verbal representations to graphs by means of a numerical transition representation in which the student translates the verbal representation to a numerical transition representation and then translates a numerical transition representation to a graphic representation. The results of this study are expected to increase the findings of previous research and consideration in designing learning model. Further research related to the type of transitional representation used by students in the translation process is still highly possible to be conducted.

\section{REFERENCES}

[1] Adu-Gyamfi, K \& Bosse, M. J., \& Stiff, L. V. (2012). Lost in Translation: Examining Translation Errors Assosiated with Mathematical Representation. School science and Mathematics, 112(3): 159-170.

[2] Bosse, M. J., Gyamfi, K. A\& Chandler, K. (2014). Students Differented Translation Processes, (Online),(http://www.cimt.plymouth.ac.uk/journal/boss e5.pdf).

[3] Uwingabire, I.,\& Takuya, B. (2014). Multiple Representasi Used By Rwandan Primary Teacher In Mathematics Lessons. Proceeding of the Joint Meeting of PME 38 and PME-NA 36, Vol. 6, p. 254.

Vancouver, Canada: PME.

[4] Osman, S. A., Razali, S. f. M., Shokri, S. N. M., Othman, A., Badaruzzaman, W. H. W., Taib, K. A., Khoiry, M. A. (2016). Effectiveness of Pre-Test in Determining Students' Achievement in Department Fundamental Courses. Pertanika Journal Social Sciences \& Humanities. Vol. 24 (S): 49-62.

[5] Bosse, M. J., Gyamfi, K. A\& Chandler, K. (2011). Assesing the Difficulty of Mathematical Translations: Synthesizing th Literature and Novel. International Electronical Journal of Mathematics Education, 6(3), 113-133.4.

[6] National Council of Teachers of Mathematics. (2000). Principles and Standards for School Mathematics. Reston, VA: NCTM.

[7] Bal, A. P. (2015). Skills Of Using And Transform Multiple Representations Of The Prospective Teachers. Journal of Mathematical Behavior. Vol. 197. Hal. 582588.

[8] Gurbuz, R\& Sahin, S. (2015). 8th Grade Students Skill in Translting Among Multiple Representations. K. U. Kastamonu Egitim Dergisi, 23(4), 1865-1884.

[9] Celik, D., Arslan, A. S. (2012). The Analysis of Teacher Candidats Translating skill in Multiple Representations, (Online), (http://ilkogretimonline.org.tr/vol11say1/v11s1m18.pdf). 
Math Ability (doctoral dissertation). Miami: University of Miami,

(Online),(http://scholarlyrepository.miami.edu/cgi/view content.cgi? article $=1454 \&$ context $=$ oa_dissertations)

Mathemathics Teaching and Learning, p 1-29. 29p.

[11] Hussein, J. Q., \& Abdullah, I. H. (2016). The Role of Cognitive Context in the Interpretation of Riddles: A Relevance Theory Perspective. Pertanika Journal Social Sciences \& Humanities. Vol. 24(S): 11-20

[12] Poch, A. L., Garderen, D. V., \& Scheuermann, A. M. (2015). Students' Understanding of Diagrams for Solving Word Problems: A Framework for Assessing Diagram Proficiency. Teaching Exceptional Children, Vol. 47, 153-162.

[13] Krawec, L.J. (2010). Problem Representation and Mathematical Problem Solving of Students of Varying
[14] Abdullah, N. Zakaria, E \& Halim, L. (2012). The Effect of a Thinking Strategy Approach through Visual Representation on Achievement and Conceptual Understanding in Solving Mathematical Word Problems.Asian Social Science, 8(16): 30-37.

[15] Cawley, A. (2016). Developmental Mathematics Students Use of Representation to Describe the Intercept of Linear Function., (Online), (http://sigmaa.maa.org/rume/crume2016/Papers/RUME _19_paper_24.pdf). 